\title{
Effect of Succinonitrile on Electrical, Structural and Thermal Properties of PVA-Based Polymer Electrolyte for Magnesium Battery
}

\author{
Belal M. Abdel-Samiea, Rania Gamal and Eslam M. Sheha \\ Physics Department, Faculty of Science, Benha University, Benha 13518, Egypt
}

Received: October 30, 2013 / Accepted: February 27, 2014 / Published: June 30, 2014.

\begin{abstract}
This paper report the synthesis and properties of a series of composite polymer electrolytes formed by dispersion of a non-ionic organic plastic material SN (succinonitrile) into poly(vinyl alcohol) complexed with magnesium acid salt. SEM (scanning electron microscope) images of different SN concentrations of films revealed that large open pore structure were also frequently present, when SN content increase up to $7.5 \mathrm{wt} \%$. The addition of SN greatly enhances ionic conductivities of the electrolytes which is due to the high polarity and diffusivity of $\mathrm{SN}$. The $\mathrm{Mg}^{2+}$ (magnesium ion) ion conduction is confirmed from impedance spectroscopy and transport number measurements. The highest conducting sample in the plasticized system was used to fabricate Mg (magnesium) battery with configuration $\mathrm{Mg} / \mathrm{SPE} / \mathrm{TiO}_{2}$. The discharge capacity of the fabricated battery was $17.5 \mathrm{mAh} / \mathrm{gm}$.
\end{abstract}

Key words: Polymer electrolyte, succinonitrile.

\section{Introduction}

Recent battery engineering has examined a number of new electrochemical systems using novel electrode materials and electrolytes. Mg (magnesium) has been considered as one such potential alternative to current battery electrode materials. It is a low cost, light and abundant element, environmentally benign and relatively easy to handle [1]. Electrochemically, $\mathrm{Mg}$ has a high theoretical specific charge capacity $(2,205 \mathrm{~A}$ $\mathrm{h} / \mathrm{kg}$ ) [2] and high theoretical energy density (3.8 A $\left.\mathrm{h} / \mathrm{cm}^{3}\right)$, making it an excellent candidate as a metal battery anode. $\mathrm{Mg}$ batteries have previously been described in Refs. [3-6].

Solid ionic conductors or solid electrolyte have some advantages in replacing liquid electrolyte, such as eliminating leakage and wide application including electrochemical display devices, power sources and so

Corresponding author: Eslam M. Sheha, associate professor, research fields: energy storage, Ionic conductivity. E-mail: ISLAM.SHIHAH@fsc.bu.edu.eg. on. In spite of the attractive advantages of conventional solid electrolytes, one of the difficulties is the loss of contact between electrode and electrolyte because of dimensional changes during the charge-discharge cycles of the battery [7].

PE (polymer electrolytes) possess the advantage of flexibility over inorganic solids. The use of all solid PE would overcome the limitations of liquid electrolytes, negate the need of separator and be processed easily [8].

It has been reported that in the plastic crystalline phase of highly polar SN (succinonitrile), various salts can be dissolved to give solid electrolytes with high ionic conductivities over a wide temperature range [911]. The presence of plasticity (i.e., easy deformation without fracture under applied stress [12]) in SN and its high degree of polarity provides a novel opportunity to develop composite polymeric systems involving plastic crystal as a solid plasticizer [13].

HPAs (heteropolyacids) are one of the most 
attractive inorganic modifiers because these inorganic materials in crystalline form have been demonstrated to be highly conductive and structure stable. PWA (Phosphotungstic acid) is one of the strongest Keggin-type heteropolyacids exhibited preferential transport for positively charged ions [14], and it was highly probable that the described conductor is magnesium conducting because $\mathrm{Mg}$ will be was one of the mobile species present in our system.

Owing to these merits, our current work is aimed at improving the electrical and electrochemical properties of the PVA (poly vinyl alcohol)/ $\mathrm{MgBr}_{2}$ (Magnesium bromide) through doping in different proportions of PWA and SN. Structure and ionic conductivity studies are performed on the solid PE. With a PE of optimum composition, solid-state $\mathrm{Mg} / \mathrm{PE} / \mathrm{TiO}_{2}$ cell is assembled, and its cycling performances will be briefly examined to evaluate the applicability of the solid polymer electrolyte to solid-state magnesium batteries. Also, we investigated the discharge process of $\mathrm{Mg} / \mathrm{TiO}_{2}$ using SEM (scanning electron microscopy), and EDX (energy dispersive X-ray spectrometer).

\section{Experimental Section}

PVA (degree of hydrolization $\geq 98 \%, \mathrm{Mw}=72,000$ ), $\mathrm{MgBr}_{2}$ and PWA were received from Sigma. The complex electrolytes were prepared by mixing of $0.4 \%$ hydroquinone (antioxidant) (w/v), 1\% (w/v) EC (ethylene carbonate), $\mathrm{PVA}, \mathrm{MgBr}_{2}$ and $\mathrm{PWA}$ at several stoichiometric ratios in distilled water to get $\mathrm{PVA}_{(1-\mathrm{x})}\left(\mathrm{MgBr}_{2}\right)_{\mathrm{x} / 2}(\mathrm{PWA})_{\mathrm{x} / 2}$ complex electrolytes, where $x$ is $0.0,0.1,0.2,0.3,0.4$ and $0.5 \mathrm{gm}$. The solutions with variable ratio were stirred vigorously and casted in Petri dish following solution cast technique at room temperature. To the highest conducting composition in the polymer-acid salt system, different amount of SN $\left(x^{\prime}\right)$ were added to produce the plasticized electrolyte system.

TGA (termogravametric analysis) was done on a Perkin-Elmer analyzer TGA-7 attached to a professional computer 7,700 from room temperature to
$400{ }^{\circ} \mathrm{C}$ with a heating rate at $10{ }^{\circ} \mathrm{C} / \mathrm{min}$.

The morphology of the polymer electrolyte was examined using scanning electron microscope, SEM (JOEL-JSM Model 5600).

Conductivity measurements were made for $\operatorname{PVA}_{(1-\mathrm{x})}\left(\mathrm{MgBr}_{2}\right)_{\mathrm{x} / 2}(\mathrm{PWA})_{\mathrm{x} / 2}$ composite polymer membrane by an ac impedance method. Samples of diameter $0.5 \mathrm{~cm}$ were sandwiched between the two similar brass electrodes of a spring-loaded sample holder. The whole assembly was placed in a furnace monitored by a temperature controller. The rate of heating was adjusted to be $2 \mathrm{~K} \cdot \mathrm{min}^{-1}$. Impedance measurements were performed on PM 6304 programmable automatic RCL (Philips) meter in the frequency ranging from $100 \mathrm{~Hz}$ to $100 \mathrm{kHz}$ at different temperatures.

$\mathrm{Mg}$ transference number $\left(t_{\mathrm{Mg}^{2+}}\right)$ was measured by the steady-state technique which involved a combination of ac and dc measurements. The ac complex impedance response of the $\mathrm{Mg} /$ electrolyte/ $\mathrm{Mg}$ cell was first measured to determine the cell resistances. It was followed by the dc polarization run, in which a small voltage pulse $(\Delta V=0.3 \mathrm{~V})$ was applied to the cell until the polarization current reached the steady-state $I_{\mathrm{s}}$. Finally, the ac impedance response of the cell was measured a gain to determine the cell resistance after dc polarization. Then $t_{M g^{2+}}$ could be calculated with the following equation [15]:

$$
t_{m g 2+}=\frac{I_{s}\left(\Delta V-R_{o} I_{o}\right)}{I_{o}\left(\Delta V-R_{s} I_{s}\right)}
$$

where, $I_{\mathrm{o}}$ and $I_{\mathrm{s}}$ are the initial and final steady-state currents and $R_{0}$ and $R_{\mathrm{S}}$ are the cell resistances before and after the polarization, respectively.

Electrodes with 70\%:30\% $\mathrm{TiO}_{2} /$ graphite and $20 \%$ electrolyte were prepared using the following protocol. A slurry obtained by mixing the $\mathrm{TiO}_{2} /$ graphite/electrolyte solution was cast. The electrode was prepared by cold pressing $0.6 \mathrm{gm}$ into a pellet of $13 \mathrm{~mm}$ in diameter under 2.5 tons $/ \mathrm{cm}^{2}$. The optimum electrolytes were deposited on the cathode substrate with a spin coater at 5,000 rpm. The anode 
was prepared by cold pressing 0.6 gm magnesium ribbon into a pellet of $13 \mathrm{~mm}$ in diameter under 2.5 tons $/ \mathrm{cm}^{2}$. Two-electrodes Swagelok test cell were assembled, the cell was discharged at room temperature on a multi-channel battery test system (NEWARE BTS-TC35) to analyze the electrochemical responses. The current density was $100 \mu \mathrm{A} / \mathrm{cm}^{2}$.

Elemental mapping of the $\mathrm{TiO}_{2}$ electrode was measured using an energy dispersive spectrometer (INCA Energy, Oxford Instruments) before and after discharge. SEM was used to observe changes in the surface morphology of the $\mathrm{TiO}_{2}$ electrode before and after discharge.

\section{Results and Discussion}

Depending on the type and amount of $\mathrm{SN}$ in the polymer matrix, the morphology of the polymer electrolyte will vary and greatly influence its properties. Morphological examination of this study is carried out to study the phase morphology changes of the pure and the resulting plasticized $\mathrm{Mg}$ acid salt polymer-electrolyte. Scanning electron micrographs of untreated and SN doped have been presented in Fig. 1. Very distinguishable changes can be observed from PE and high concentrations of SN doped PE. Pure PE shows smooth surface. The morphology changes, as soon as $\mathrm{SN}$ is incorporated into the polymer. The morphology changes drastically to become significantly more layered and even greater pore size. An open pore structure of the polymer electrolyte matrix is essential for ionic conductivity across the thin film. This type of open porous structure provides enough channels for the migration of ions, accounting for better ionic conductivity [16].

Fig. 2 shows TGA thermograms of weight loss as a function of temperature for $\mathrm{Mg}$ acid salt polymer electrolyte and their complexes with $\mathrm{SN}$ a heating rate of $10{ }^{\circ} \mathrm{C} / \mathrm{min}$ in the temperature range from room temperature to $400^{\circ} \mathrm{C}$. It is clear that, the initial weight loss for all the samples occurs due to the moisture evaporation. The major weight losses are observed in the range of $120-210{ }^{\circ} \mathrm{C}$ for all the prepared samples. This may be correspondent to the structural decomposition of the polymer blends and their complexes.

Activation energy for the thermal decomposition of the present samples depends on the residual mass can be calculated using integral equation of Coates and Redfern [17, 18]:

$$
\begin{aligned}
& \log \left[\frac{1-(1-\alpha)}{T^{2}}\right]= \\
& \log \frac{R}{\Delta E_{a}}\left[1-\frac{2 R T}{E_{a}}\right]-0.434 \frac{E_{a}}{R T}
\end{aligned}
$$

where, $T$ is the absolute temperature in Kelvin, $E_{a}$ is the activation energy in $\mathrm{J} / \mathrm{mol}, R$ is the universal gas constant $(8.31 \mathrm{~J} / \mathrm{mol} \mathrm{K})$, is the order of reaction and the fraction of conversion, $\alpha$, for a weight loss, is given by:

$$
\alpha=\frac{w_{i}-w_{a}}{w_{i}-w_{f}}
$$

where, $w_{a}, w_{i}$ and $w_{f}$ are the actual, initial and final weight of the samples, respectively. By plotting the
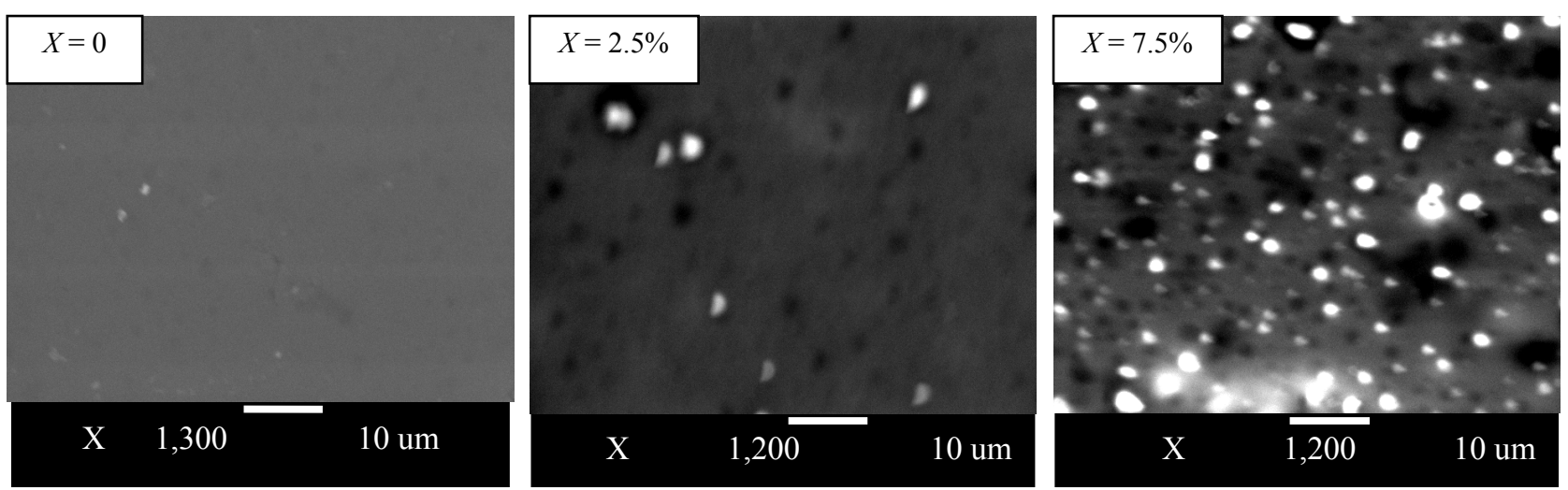

Fig. 1 The SEM micrograph for the surface of $\mathrm{PVA}_{0.5}\left(\mathrm{MgBr}_{2}\right)_{0.25}(\mathrm{PWA})_{0.25} /(\mathrm{SN})_{\mathrm{x}^{\prime}}$ acid salt membrane. 


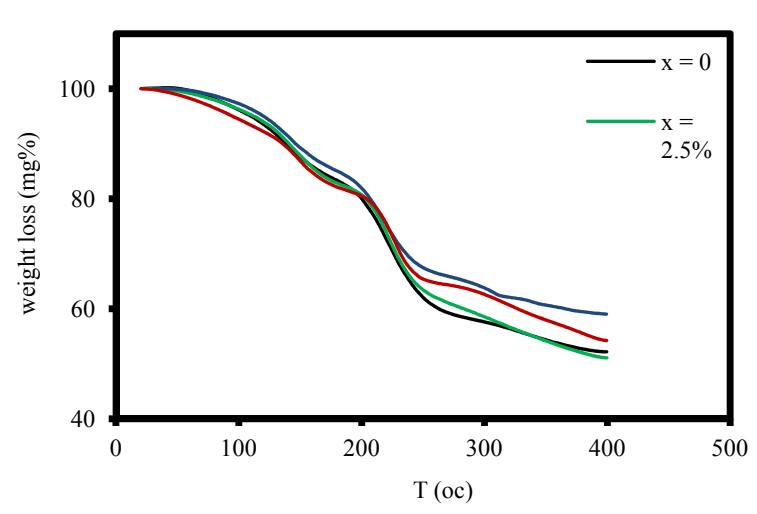

Fig. 2 TGA thermograms of weight loss as a function of temperature.

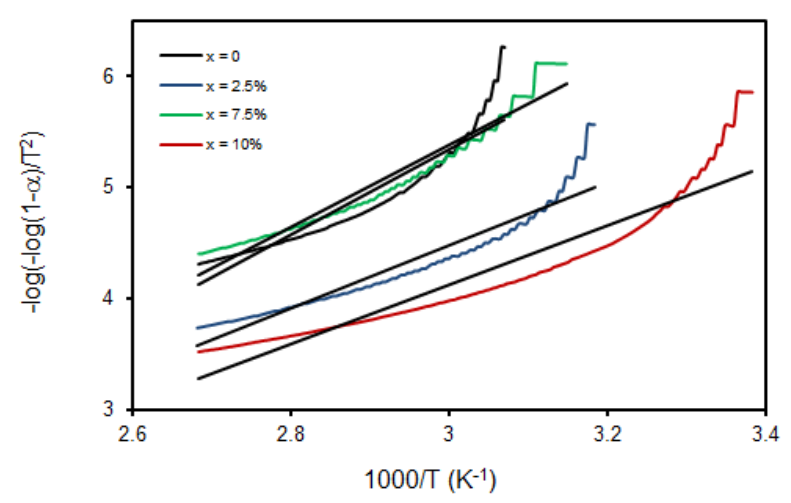

(a)

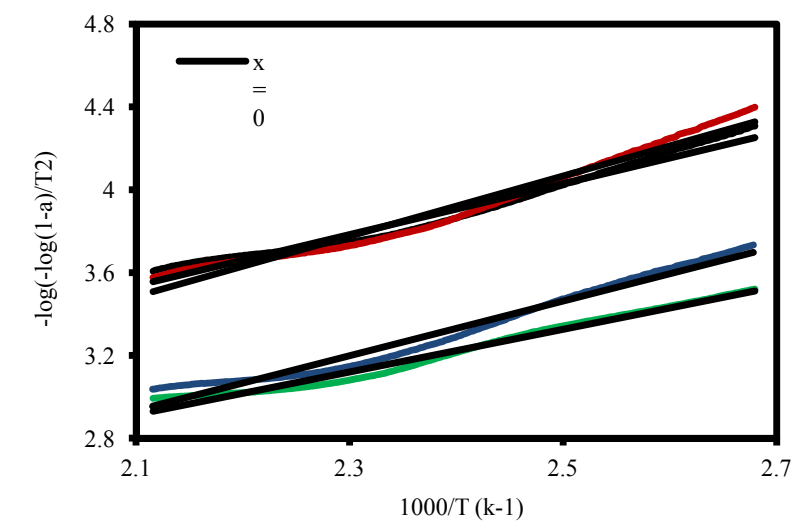

(b)

Fig. 3 Thermal activation plot (a) from $20-100{ }^{\circ} \mathrm{C}$ and (b) from $100-200{ }^{\circ} \mathrm{C}$.

dependence of $-\log \left[\frac{-\log (1-\alpha)}{T^{2}}\right]$ versus $\frac{1,000}{T}$ for each sample as shown in Figs. $3 a$ and 3b, we obtain straight lines. Then, the apparent activation energies are calculated from the slopes of these lines using the expression

$$
E_{a}=2.303 R \times \text { slope }
$$

Values of the apparent activation energy of the samples are listed in Table 1. From this table, it clears that, values of the activation energy decreased with increase SN content.

This can be attributed to the low melting point of SN at around $57^{\circ} \mathrm{C}[13]$.

A typical result of $\mathrm{dc}$ and ac measurement for determining for $\left(\mathrm{PVA}_{(0.5)}\left(\mathrm{MgBr}_{2}\right)_{0.25}(\mathrm{PWA})_{0.25}\right) / 7.5 \mathrm{wt} \% \mathrm{SN}$ polymer electrolyte is shown in Fig. 4. The dc polarization current needs about $3 \mathrm{~h}$ to reach the steady state. After dc polarization, $R_{0}$ increases from $5 \times 10^{4} \Omega$ to $7 \times 10^{4}$ $\Omega$. The value of $t_{M g^{2+}}$, is evaluated using Eq. (1), has been found to be $\cong 0.67$ at room temperature.

Fig. 5 shows the Cole-ole plot for $\operatorname{PVA}_{(1-\mathrm{x})}\left(\mathrm{MgBr}_{2}\right)_{\mathrm{x} / 2}(\mathrm{PWA})_{\mathrm{x} / 2}$ (Fig. 5a) and plasticizes (PVA) 0.5 (PWA) $0.25\left(\mathrm{MgBr}_{2}\right)_{0.25} / \mathrm{SN}$ (Fig. 5b) PE at 293 $\mathrm{k}$. The Cole-Cole plot for $\mathrm{PVA}_{(1-\mathrm{x})}\left(\mathrm{MgBr}_{2}\right)_{\mathrm{x} / 2}(\mathrm{PWA})_{\mathrm{x} / 2}$ shows semicircle implying that the material is partially

Table 1 Activation energy for the thermal decomposition of untreated and $\mathrm{SN}$ doped membrane.

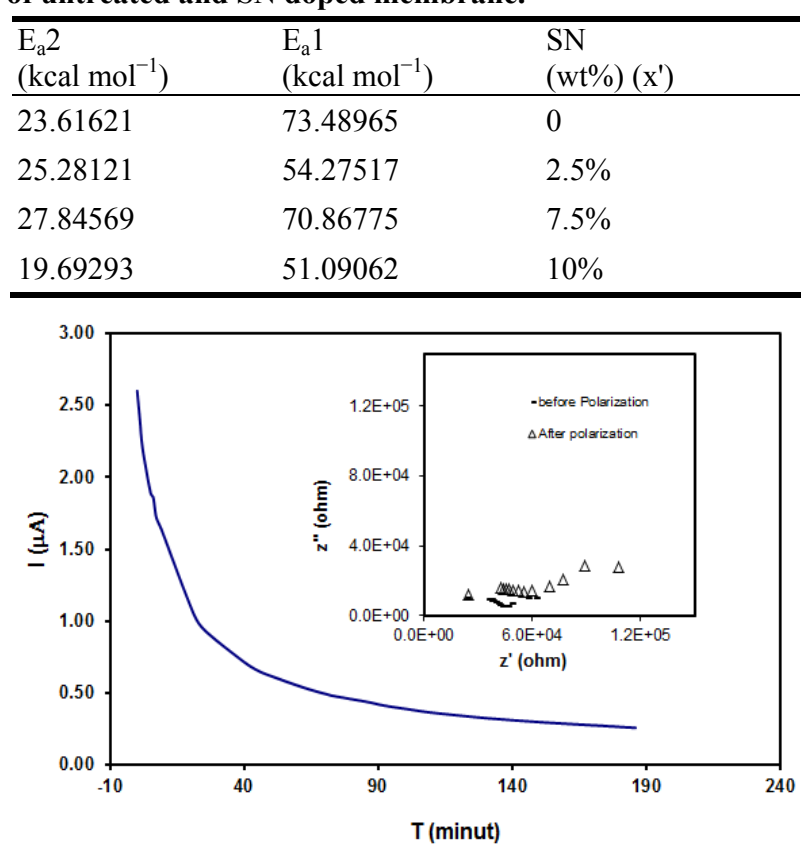

Fig. 4 The de polarization current of $\mathrm{Mg} / \mathrm{PE}$ with $7.5 \mathrm{wt} \%$ $\mathrm{SN} / \mathrm{Mg}$ symmetric cell at $20^{\circ} \mathrm{C}$, where the inset shows the ac complex impendence before and after dc polarization. 


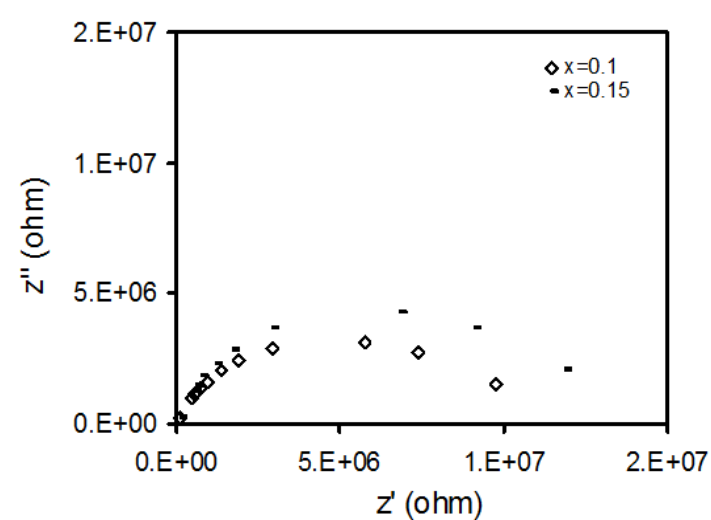

(a)

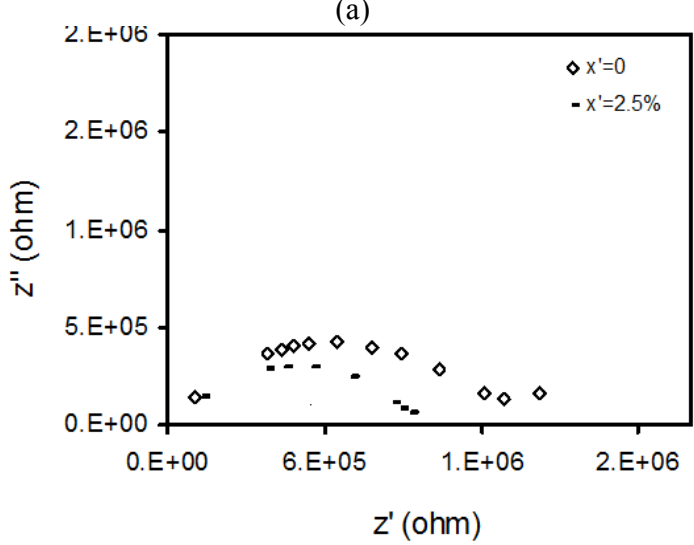

(b)

Fig. 5 Cole-Cole plots for $\operatorname{PVA}_{(1-\mathrm{x})}\left(\mathrm{MgBr}_{2}\right)_{\mathrm{x} / 2} \mathbf{P W A}_{(\mathrm{x} / 2)} \mathbf{S N}_{\left(\mathrm{x}^{\prime}\right)}$ films (a) $x=0.1,0.15, x^{\prime}=0$; (b) $x=0.5, x^{\prime}=0,2.5$.

resistive and capacitive. However, samples containing both acid salt and SN show low frequency spike is due to the diffusion process. The ionic conductivity is calculated according to $\sigma_{b}=\frac{1}{R_{b}} \times \frac{L}{A}$

where, $L$ is the thickness of the PE film, $A$ is the surface area of the film and $R_{b}$ is the bulk electrical resistance value, which can be calculated from the intercept on the $Z^{\prime}$ axis.

The effect of acid salt (PWA) $\left(\mathrm{MgBr}_{2}\right)$ composition on ionic conductivity of pure PVA film is shown in Fig. 6a. The conductivity of pure PVA film is low about $10^{-10} \mathrm{~s} \cdot \mathrm{cm}^{-1}$ at room temperature. The ionic conductivity is observed to increase gradually until $10^{-7}$ $\mathrm{s} \cdot \mathrm{cm}^{-1}$ when $40 \mathrm{wt} \%$ acid salt was added. The increase in conductivity is attributable to the increase in acid salt content which can dissociate to provide more mobile ion as more acid salt is added, which contributes to increase in conductivity. The effect of $\mathrm{SN}$ on ionic

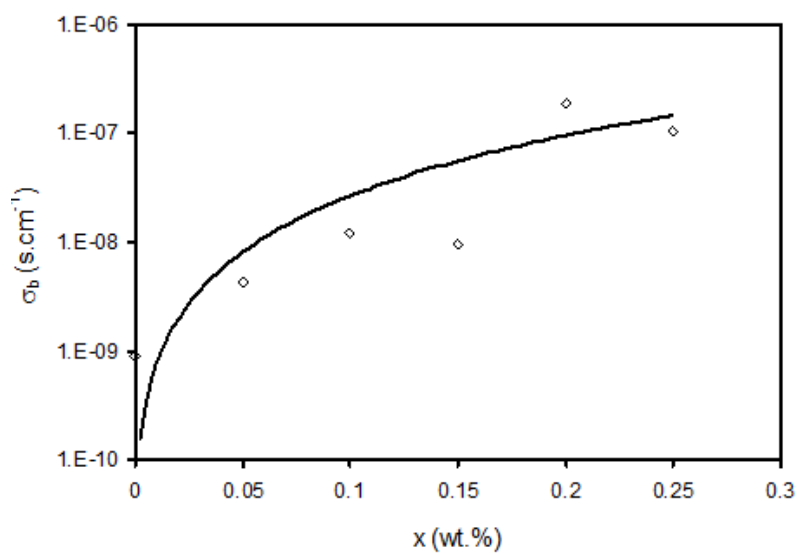

(a)

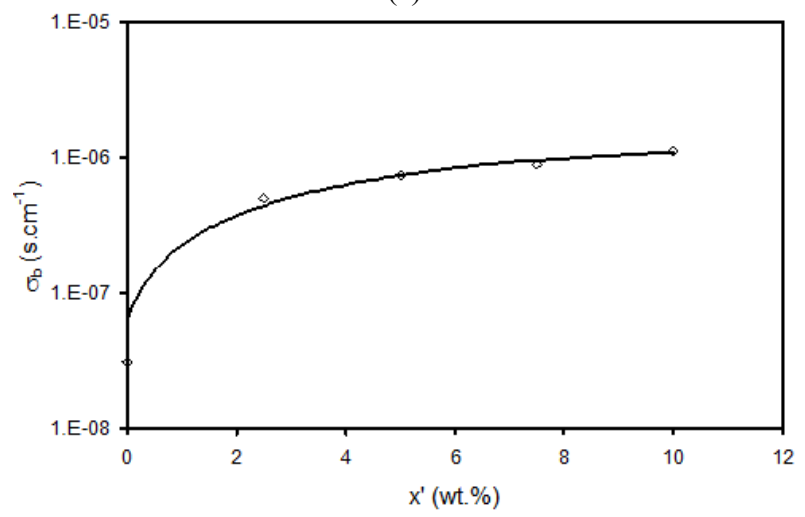

(b)

Fig. 6 the ionic conductivity of PVA with various concentrations of (a) $x^{\prime}=0$ and $x \neq 0$, (b) $x=0.5$ and $x^{\prime} \neq 0$.

conductivity of $(\mathrm{PVA})_{0.5}(\mathrm{PWA})_{0.25}\left(\mathrm{MgBr}_{2}\right)_{0.25}$ is shown in Fig. 6b.

The conductivity of (PVA $)_{0.5}(\mathrm{PWA})_{0.25}\left(\mathrm{MgBr}_{2}\right)_{0.25}$ is low about $10^{-7} \mathrm{~s} \cdot \mathrm{cm}^{-1}$ at room temperature. The ionic conductivity is observed to increase gradually until $10^{-6}$ $\mathrm{s} \cdot \mathrm{cm}^{-1}$ when $10 \mathrm{wt} \% \mathrm{SN}$ was added. The ionic conductivity enhancement can be attributed to the decrease in crystallenity of (PVA $)_{0.5}(\mathrm{PWA})_{0.25}\left(\mathrm{MgBr}_{2}\right)_{0.25}$ polymer electrolyte as observed in TGA as well as the high polarity and diffusivity of SN.

The first discharge curves of a $\mathrm{Mg}$ /electrolyte $/ \mathrm{TiO}_{2}$ cell at room temperature is given in Fig. $7 \mathrm{a}$ and $7 \mathrm{~b}$. The $\mathrm{Mg} /$ electrolyte $/ \mathrm{TiO}_{2}$ cell shows a discharge capacity $17.5 \mathrm{mAh} / \mathrm{gm}$. An investigation was made of surface of the $\mathrm{TiO}_{2}$ electrode by means of SEM, and EDX in order to determine the reaction in the electrodes. The SEM morphology of the original $\mathrm{TiO}_{2}$ electrode before discharge is given in Fig. 8a.The surface consists of a 


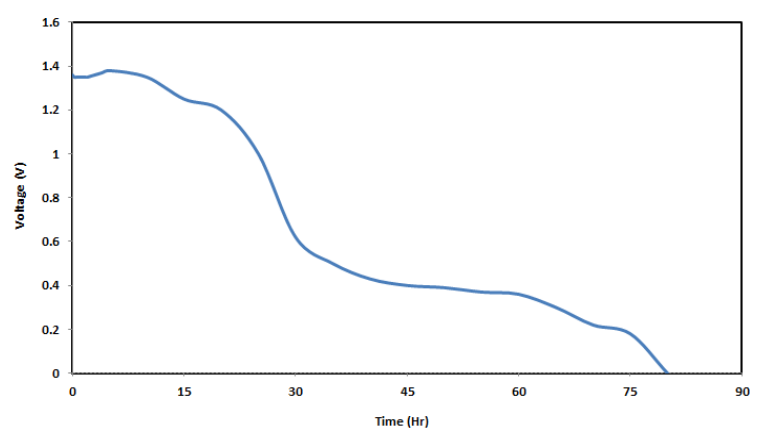

(a)

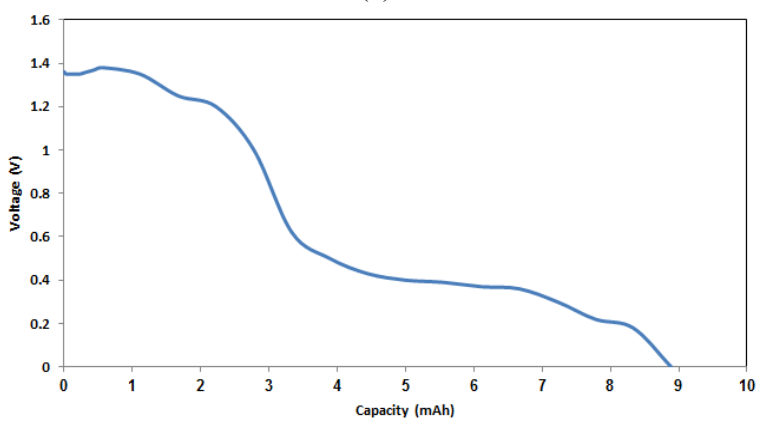

(b)

Fig. 7 Discharge curve of $\mathrm{Mg} / \mathrm{PE} / \mathrm{TiO}_{2}$ cell (a) discharge voltage against time, and (b) discharge voltage against capacity.

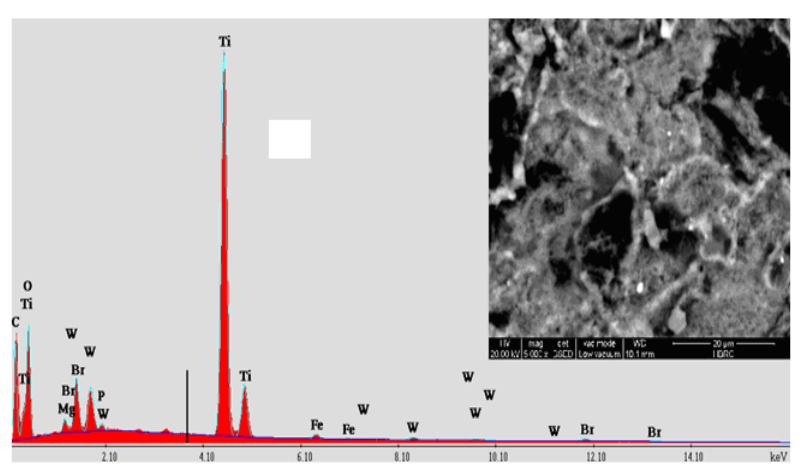

(a)

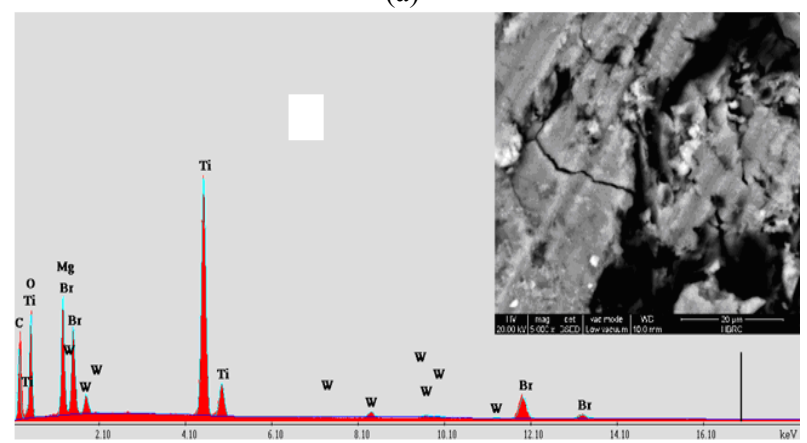

(b)

Fig. 8 EDAX \& SEM images of Titanium dioxide electrode (a) before discharge; (b) after the first discharge.

Table 2 EDX results of $\mathrm{TiO}_{2}$ electrode before and after discharge.

\begin{tabular}{llllllll}
\hline $\begin{array}{l}\text { K-ratio } \\
\text { discharge }\end{array}$ & Normal & $\begin{array}{l}\text { At } \% \\
\text { discharge }\end{array}$ & Normal & $\begin{array}{l}\mathrm{Wt} \% \\
\text { discharge }\end{array}$ & Normal & Element \\
\hline 0.0730 & 0.0882 & 53.43 & 46.00 & 34.76 & 26.74 & $\mathrm{~K}$ & $\mathrm{C}$ \\
0.0354 & 0.0383 & 30.37 & 36.04 & 24.80 & 27.91 & $\mathrm{~K}$ & $\mathrm{O}$ \\
0.0279 & 0.0036 & 5.11 & 0.66 & 6.34 & 0.78 & $\mathrm{~K}$ & $\mathrm{Mg}$ \\
--- & 0.0026 & --- & 0.24 & ---36 & $\mathrm{~K}$ & $\mathrm{P}$ \\
0.1414 & 0.3162 & 6.58 & 15.05 & 16.09 & 34.88 & $\mathrm{~K}$ & $\mathrm{Ti}$ \\
--- & 0.0070 & --- & 0.30 & ---8.81 & $\mathrm{~K}$ & $\mathrm{Fe}$ & $\mathrm{L}$ \\
0.0229 & 0.0239 & 0.30 & 0.37 & 2.84 & 3.32 & $\mathrm{~W}$ \\
0.1416 & 0.0421 & 4.21 & 1.35 & 17.17 & 5.23 & $\mathrm{~K}$ & $\mathrm{Br}$ \\
--- & --- & 100.00 & 100.00 & 100.00 & 100.00 & $\mathrm{Total}$ & \\
\hline
\end{tabular}

homogenous mixing of powders such as $\mathrm{TiO}_{2}$, graphite, and electrolyte materials (20\%). The surface of electrode after discharge (Fig. 8b) is smooth and covered with materials that are product of reactants, such as $\mathrm{Mg}_{\mathrm{x}} \mathrm{TiO}_{2}$.

Table 2 lists EDX results for the $\mathrm{TiO}_{2}$ electrodes before and after discharge. After discharge, the contents of $\mathrm{Mg}$ from increase $0.78 \%$ to $6.34 \%$ in the $\mathrm{TiO}_{2}$ electrodes. The content of Oxygen decreases from $27.91 \%$ to $24.80 \%$. The ratio of $\mathrm{Mg}$ to $\mathrm{Ti}$ is about
$0.394 \%$, therefore the final product might be $\mathrm{Mg}_{\mathrm{x}} \mathrm{TiO}_{2}$.

\section{Conclusions}

The approach of combining a polymer and a plastic crystal to generate a new type of magnesium ion conductor have been succeded. The result can summarized as follow:

The addition of SN can obviously increase the free volume of the polymer electrolyte, thus enhances the 
ionic conductivity of the polymer. Further optimization with regard to materials processing and choice of acid salt and polymer would lead to possible application of the present plastic polymer composites for magnesium battery.

The ionic conductivity depended on the content of $\mathrm{SN}$. The highest conductivity of the PE examined was $1.13 \times 10^{-6} \mathrm{~s}^{\cdot \mathrm{cm}^{-1}}$ (at $20^{\circ} \mathrm{C}$ ) for the composition of 10 $\mathrm{wt} \% \mathrm{SN}$.

The cell capacity of $\mathrm{TiO}_{2} / \mathrm{PE} / \mathrm{Mg}$ is $17.5 \mathrm{mAh} / \mathrm{gm}$.

Further extensive investigations are required, however, to raise the performance of the magnesium-based rechargeable cells to practical levels.

\section{Acknowledgment}

We are grateful to the Science technology development fund of Egypt, grant number 2069.

\section{References}

[1] I.J. Polmear, Light Alloys: Metallurgy of the Light Metals, 3rd ed., Edward Arnold, London, 1995.

[2] J.O. Besenhard, M. Winter, Advances in battery technology: Rechargeable magnesium batteries and novel negative-electrode materials for lithium ion batteries, Chem. Phys. Chem. 3 (2002) 155-159.

[3] B. Winther-Jensen, M. Gaadingwe, D.R. Macfarlane, M. Forsyth, Control of magnesium interfacial reactions in aqueous electrolytes towards a biocompatible battery, Electrochimica Acta. 53 (2008) 5881-5884.

[4] S. Sathyanarayana, N. Munichandraiah, A new magnesium-Air cell for long-life applications, J. Appl. Electrochem 11 (1981) 33-39.

[5] W. Li, C. Li, C. Zhou, H. Ma, J. Chen, Metallic magnesium nano/mesoscale structures: Their shape-controlled preparation and $\mathrm{Mg} / \mathrm{Air}$ battery Applications, Angew. Chem., Int. Ed. 45 (2006) 6009-6012.

[6] T. Khoo, P.C. Howlett, M. Tsagouria, D.R. MacFarlane,
M. Forsyth, The potential for ionic liquid electrolytes to stabilise the magnesium interface for magnesium/air batteries, Electrochimica Acta 58 (2011) 583-588.

[7] D.E. Fenton, J.M. Parker, P.V. Wright, Complexes of alkali metal ions with poly(ethylene oxide), Polymer 14 (1973) 589-592.

[8] S. Zhou, S. Fang, High ionic conductivity of all-solid polymer electrolytes based on polyorganophosphazenes, European Polymer Journal 43 (2007) 3695-3700.

[9] E. Sheha, Prototype system for magnesium $/ \mathrm{TiO}_{2}$ anatase batteries., Int. J. Electrochem. Sci. 8 (2013) 3653-3663.

[10] S. Long, D.R. MacFarlane, M. Forsyth, Fast ion conduction in molecular plastic crystals, Solid State Ionics 161 (2003) 105-112.

[11] P.J. Alarco, Y. Abu-Lebdeh, A. Abouimrane, M. Armand, The plastic-crystalline phase of succinonitrile as a universal matrix for solid-state ionic conductors, Nat. Mater 3 (2004) 476-481.

[12] J. Sherwood, The Plastically Crystalline State, Wiley, London, 1979.

[13] L.Z. Fan, J. Maier, Composite effects in poly(ethylene oxide)-Succinonitrile based all-solid electrolytes, Electrochemistry Communications 8 (2006) 1753-1756.

[14] Z. Li, Y. Liu, H. Liu, P. He, Q. Zhang, J. Li, Synthesis and ionic conductivity of polymeric ion gel containing room temperature ionic liquid and phosphotungstic acid, Solid State Ionics 177 (2006) 1281-1286.

[15] G. P. Pandey, R. C. Agrawal, S. A. Hashmi, Magnesium ion-conducting gel polymer electrolytes dispersed with fumed silica for rechargeable magnesium battery application, J. Solid State Electrochemistry 15 (2011) 2253-2264.

[16] S. Ramesh, S.C. Lu, Structural, morphological, thermal, and conductivity studies of magnesium ion conducting $\mathrm{P}(\mathrm{VdF}-\mathrm{HFP})$-based solid polymer electrolytes with good prospects, J. Applied Polymer Science 117 (2010) 2050-2058.

[17] T.K. Kwei, The effect of hydrogen bonding on the glass transition temperatures of polymer mixtures, J. Polym. Sci.: Polym. Lett. Ed 22 (1984) 307-313.

[18] E.M. Abdelrazek, I.S. Elashmawi, A. El-khodary, A. Yassin, Structural, optical, thermal and electrical studies on PVA/PVP blends filled with lithium bromide, Current Applied Physics 10 (2010) 607-613. 